\title{
EVALUASI DAN HASIL REVIEW DESAIN USER INTERFACE PROTOTYPE APLIKASI MOBILE SITTA UNIVERSITAS TERBUKA
}

\author{
Unggul Utan Sufandi ${ }^{1}$, Dwi Astuti Aprijani ${ }^{2}$, Paken Pandiangan ${ }^{3}$ \\ ${ }^{1}$ Prodi Sistem Informasi, Universitas Terbuka \\ ${ }^{2}$ Prodi Sistem Informasi, Universitas Terbuka \\ ${ }^{3}$ Prodi Pendidikan Fisika, Universitas Terbuka
}

email: unggul@ecampus.ut.ac.id ${ }^{1}$, dwias@ecampus.ut.ac.id ${ }^{2}$, pakenp@ecampus.ut.ac.id ${ }^{3}$

\begin{abstract}
Abstrak
Sistem Informasi Tiras dan Transaksi Bahan Ajar (SITTA) merupakan sistem yang dimiliki Universitas Terbuka (UT) untuk mengelola layanan dan distribusi bahan ajar ke mahasiswa. Saat ini, sistem tersebut sedang dikembangkan dalam versi mobile berbasis platform Android. Aplikasi mobile SITTA dikembangkan dengan langkah awal berupa pembuatan desain prototype aplikasi. Suatu desain aplikasi perlu dilakukan evaluasi agar aspek-aspek usability dapat sesuai dengan prinsip desain User Interface dan User Experience yang baik dan benar untuk memenuhi kebutuhan user secara tepat. Penelitian ini menghasilkan hasil akhir berupa desain yang telah dievaluasi oleh pakar UI/UX Designer sebagai evaluator untuk memberikan masukkan perbaikan terhadap desain yang dirancang. Penelitian ini menggunakan pendekatan User Centered-Design dan diperoleh rancangan desain arsitektur informasi, rancangan desain user interface dalam bentuk low fidelity prototype (wireframe) dan rancangan desai user interface dalam bentuk high fidelity prototype aplikasi mobile SITTA sebagai desain rancangan yang dibuat berdasarkan evaluasi oleh pakar sesuai prinsip desain.
\end{abstract}

Kata kunci: Desain Antarmuka, Evaluasi Desain, Prototipe Aplikasi Mobile

\begin{abstract}
The Information System for Teaching Materials and Transactions (SITTA) is a system owned by the Open University (UT) to manage services and distribution of teaching materials to students. Currently, the system is being developed in a mobile version based on the Android platform. The SITTA mobile application was developed with the initial step of making an application prototype design. An application design needs to be evaluated so that usability aspects can be in accordance with the principles of good and correct User Interface and User Experience design to meet user needs appropriately. This research produces a final result in the form of a design that has been evaluated by a UI/UX Designer expert as an evaluator to provide input for improvements to the designed design. This study uses a User CenteredDesign approach and obtained an information architecture design design, a user interface design design in the form of a low fidelity prototype (wireframe) and a user interface design in the form of a high fidelity prototype for the SITTA mobile application as a design design based on an evaluation by experts according to design principle.
\end{abstract}

Keywords : Interface Design, Design Evaluation, Mobile Application Prototype

Diterima Redaksi: 13-10-2021 | Selesai Revisi: 16-12-2021 | Diterbitkan Online: 31-12-2021 DOI: https://doi.org/10.23887/janapati.v10i3.40281

\section{PENDAHULUAN}

Perkembangan dan penerapan teknologi informasi dalam bidang akademik semakin luas dan mencakup berbagai aktivitas. Dengan pemanfaatan teknologi informasi, suatu sistem informasi dapat digunakan untuk memperoleh data dan informasi yang real time dan membuat pekerjaan menjadi lebih efektif dan efisien (Laudon, 2008). Penggunaan aplikasi berbasis web telah banyak digunakan dalam bidang akademik. Sebagai contoh, Universitas Terbuka (UT) telah menggunakan sistem informasi 
berbasis web untuk kebutuhan layanan dan distribusi bahan ajar kepada mahasiswa, yaitu aplikasi web Sistem Informasi Tiras dan Transaksi Bahan Ajar atau dikenal dengan web SITTA, yang dapat diakses pada jaringan lokal UT dengan alamat https://distribusi.ut.ac.id/.

Hadirnya SITTA dalam bentuk aplikasi web dapat menjadi solusi yang tepat untuk mendukung kelangsungan kegiatan operasional dalam layanan dan distribusi bahan ajar ke mahasiswa. Aplikasi web SITTA digunakan pertama kali pada awal tahun 2018. Aplikasi dapat digunakan dalam cakupan internal UT oleh pegawai yang memiliki hak akses (user). User terdiri dari pegawai UT, baik di Kantor Pusat UT (di Pondok Cabe-Tangerang Selatan) maupun di daerah (Unit Program Belajar Jarak Jauh/ UPBJJ-UT di 39 kota Indonesia).

Pengembangan aplikasi SITTA terus dilakukan sebagai wujud inovasi teknologi informasi. Dari versi web yang telah ada, SITTA dikembangkan dalam versi mobile berbasis platform Android. Penggunaan aplikasi berbasis mobile dapat menjadi solusi bagi user SITTA untuk dapat mengakses informasi terkait layanan bahan ajar dalam satu perangkat mobile yang praktis dan mudah hanya dalam satu genggaman yang bersifat accessable.

Aplikasi mobile menurut penelitian yang telah dilakukan sebelumnya oleh K. A. Seputra dan G. Sandiasa [1] adalah software yang dirancang untuk dapat berfungsi pada perangkat bergerak salah satunya yaitu smartphone. Smartphone memiliki kemampuan mobile computing yang dapat dengan mudah membuat pengguna menambahkan fungsi/fitur aplikasi sesuai kebutuhan dengan performa yang cukup tinggi.

Aplikasi mobile SITTA merupakan sebuah aplikasi yang dikembangkan dan dirancang untuk memenuhi kebutuhan manajemen dan staff UT sebagai user aplikasi saat mengakses laporan progress pekerjaan terkait layanan bahan ajar UT ke mahasiswa dan kebutuhan informasi lainnya seperti stok bahan ajar dan fasilitas tracklacak pengiriman bahan ajar ke mahasiswa. Aplikasi mobile ini dirancang dengan usulan menu/fasilitas informasi pada aplikasi diantaranya sebagai berikut:

1. Infomasi stok bahan ajar Pusat dan UPBJJ UT

2. Informasi penggunaan bahan ajar Pusat dan UPBJJ UT

3. Informasi tracking/lacak pengiriman bahan ajar UT ke mahasiswa

4. Informasi laporan progress pekerjaan dan pengiriman $\mathrm{DO}$

5. Informasi histori tracking/pengiriman bahan ajar ke mahasiswa.
Aplikasi mobile yang baik, harus memiliki User Interface (UI) dan User Experience (UX) yang baik agar dapat memenuhi kebutuhan dan kepuasan user. Produk aplikasi yang baik, dalam platform mobile atau website adalah produk yang terus melakukan evaluasi. Hal itu berarti, iterasi evaluasi tidak berhenti hanya sampai selesainya penelitian[2]. Berdasarkan penelitian yang dilakukan sebelumnya [3] telah dijelaskan bahwa menerapkan requirement engineering untuk menghasilkan spesifikasi fitur yang baik saja tidak cukup. Sesuai dengan pengamatan peneliti yang telah dilakukan, masalah konsistensi dan standar dalam penggunaan ikon belum diaplikasikan dengan baik pada Aplikasi Mobile SITTA versi 1.0. Oleh karena itu, perlu dilakukan evaluasi Aplikasi Mobile SITTA agar memiliki UX yang lebih userfriendly. Seperti yang telah dipaparkan pada buku Human Computer Interaction oleh Dix [4] bahwa salah satu tujuan utama evaluasi adalah untuk mengidentifikasi masalah spesifikasi sistem.

Pendekatan yang dilakukan pada penelitian evaluasi desain user interface prototype aplikasi mobile SITTA yaitu dengan menggunakan Human-Centered Design. Pendekatan ini dirancang untuk sebuah desain aplikasi yang beorientasi kepada manusia sebagai user sehingga UX Designer dapat mengetahui kebutuhan pengguna aplikasi secara langsung dan nyata [3]. Penelitian ini menggunakan pakar(expert) UI/UX sebagai evaluator untuk melakukan evaluasi rancangan desain UI/UX secara teori sehingga UX Designer dapat menghasilkan desain solusi yang baik dan benar sesuai prinsip Heuristik. Harapan yang ingin dicapai pada penelitian ini yaitu desain solusi dan perancangan yang dihasilkan dari proses evaluasi oleh pakar dapat meningkatkan nilai UX secara positif bagi user dan keberlangsungan pengembangan aplikasi mobile SITTA berbasis Android untuk penelitian selanjutnya.

\section{METODE}

Pada bagian ini menjelaskan mengenai tahapan penelitian evaluasi desain user interface prototype aplikasi mobile SITTA yang dilakukan berdasarkan metode penelitian yang telah ditentukan dan digunakan untuk melakukan evaluasi desain prototype user interface aplikasi. Metode yang digunakan pada penelitian ini dapat digambarkan seperti pada Gambar 1.

Tahapan penelitian yang dilakukan memiliki penjelasan sebagai berikut:

1. Studi Literatur

Studi literature pada penelitian ini dilakukan dengan membaca dan mempelajari teori terkait 
evaluasi desain user interface aplikasi mobile untuk dijadikan referensi dan memperoleh landasan teori yang dapat mendukung kegiatan penelitian.

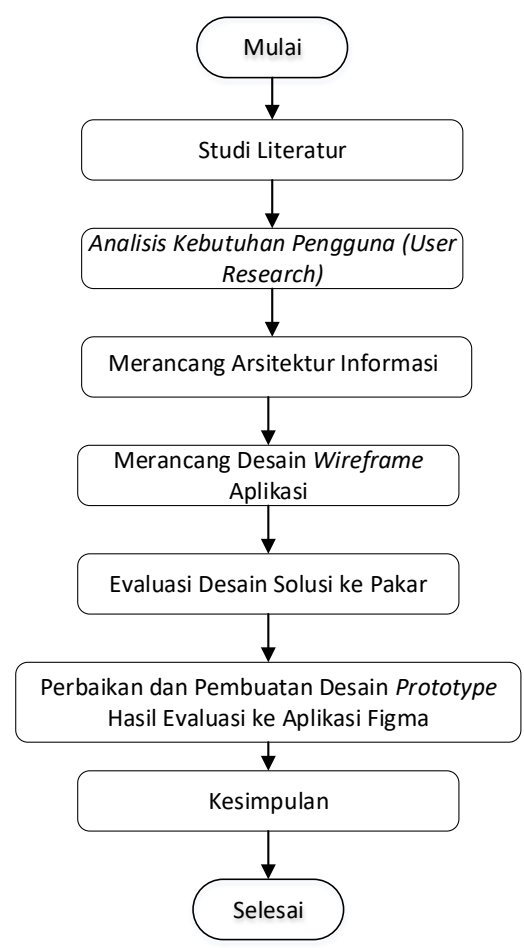

Gambar 1. Tahapan Penelitian

2. Analisis Kebutuhan UI/UX

Pada tahapan analisis kebutuhan UI/UX meliputi tahapan analisis kebutuhan UI/UX yang berfokus pada kebutuhan user ketika menggunakan aplikasi SITTA berbasis mobile untuk memperoleh hasil yang optimal pada rancangan desain aplikasi menggunakan pendekatan User Centered-Design. Pada tahap ini dilakukan research terkait kebutuhan dan perilaku pengguna dalam menggunakan teknologi dengan menggunakan teknik dasar yaitu survey dan observasi ke pengguna. Pada tahap ini juga dilakukan pembuatan user requirements untuk mengetahui fitur apa saja yang user butuhkan pada aplikasi mobile SITTA nanti kedepannya sebagai optimalisasi layanan bahan ajar di Universitas Terbuka.

3. Arsitektur Informasi dan Desain

Pada tahap ini dilakukan pembuatan informasi arsitektur aplikasi sebagai dasar dalam membuat wireframe aplikasi. Informasi arsitektur dibuat untuk menggambarkan model atau konsep informasi aplikasi. [5] Arsitektur informasi pada pembuatan desain prototype aplikasi mobile SITTA dibuat secara spesifik untuk menunjukan bagaimana user akan menemukan informasi melalui struktur navigasi aplikasi yang dibuat.

4. Merancang Desain Wireframe Aplikasi

Merancang wireframe aplikasi dilakukan berdasarkan arsitektur informasi. Hasil yang diperoleh pada tahapan ini adalah desain rancangan prototype aplikasi dalam bentuk low fidelity prototype (wireframe) menggunakan tools Whimsical.

5. Evaluasi Desain Solusi ke Pakar

Evaluasi desain solusi dilakukan untuk menemukan permasalahan user interface yang perlu disempurnakan lebih lanjut. Pada tahap evaluasi desain solusi ini tersaji dalam bentuk daftar catatan perbaikan oleh pakar yang mengambarkan temuan permasalahan berdasarkan desain wireframe yang telah dibuat dan ditunjukkan ke pakar.

6. Perbaikan dan Pembuatan Desain Prototype

Hasil Evaluasi ke Aplikasi Figma.

Pada tahap ini, dilakukan perbaikan desain user interface berdasarkan catatan perbaikan oleh pakar. Perbaikan dilakukan sebagai solusi hasil rancangan desain prototype.

7. Kesimpulan

Penarikan kesimpulan dilakukan dengan menjawab rumusan masalah yang menjadi intisari penelitian secara umum. Kemudian, penulisan saran dilakukan dengan menjelaskan hal-hal apa saja yang dinilai masih kurang dalam penelitian agar bermanfaat untuk proses penelitian selanjutnya.

\section{HASIL DAN PEMBAHASAN}

\section{1) Analisis Kebutuhan Pengguna}

Pada tahapan penelitian dengan menggunakan pendekatan Human-Centered Design memiliki tahapan analisis kebutuhan pengguna yang memiliki penjelasan yaitu membuat User Requirements kemudian diterjemahkan dan diimplementasikan ke dalam bentuk desain. Penelitian sejenis yang telah dilakukan sebelumnya diantaranya berjudul " Perancangan Desain User Interface dan User Experience pada Aplikasi SIAKAD dengan Menggunakan Metode User Centered Design (UCD) pada Universitas Islam Negeri Sunan Ampel Surabaya [6]. Tujuan penelitian ini yaitu menghasilkan rancangan user interface dan user experience pada aplikasi SIAKAD dengan metode User Centered Design (UCD). Penelitian yang telah dilakukan oleh El Ghiffary (2018) juga merupakan penelitian terkait yang sejenis 
dengan penelitian ini karena memiliki fokus terhadap desain antarmuka untuk aplikasi mobile dengan fokus analisis terhadap 3 komponen utama user interface yaitu layout, warna dan kontrol.

Sebelum menerapkan rancangan desain solusi diperlukan pedoman yang sesuai sebagai acuan dasar yang memperkuat masukkan pakar/ evaluator. Pedoman yang digunakan adalah Google Material Design. Saran perbaikan evaluator dapat diimplementasikan sebagai desain solusi ketika telah sesuai dengan pedoman dari Google Material Design.

Pada tahap ini dilakukan penyusunan setiap kebutuhan pengguna yang kemudian kebutuhan-kebutuhan tersebut didiskusikan kepada stakeholder. Tujuan dari tahap ini yaitu untuk mengambil keputusan dalam melakukan desain prototype user interface aplikasi mobile SITTA. Hasil dari tahapan ini yaitu terkait kebutuhan user untuk mencapai tujuannya dalam menggunakan aplikasi mobile SITTA.

Pada perbaikan desain user interface dengan menggunakan metode HumanCentered Design, dilakukan terlebih dahulu observasi dan wawancara kepada stakeholder yang relevan dan memahami sistem SITTA secara keseluruhan.

Tugas yang diujikan ditentukan sesuai dengan fungsi yang ada pada rancangan Aplikasi Mobile SITTA seperti pada Tabel 1.

Tabel 1. Daftar Tugas Pengguna

\begin{tabular}{ll}
\hline No & \multicolumn{1}{c}{ Tugas/ Instruksi } \\
\hline 1 & Sekarang anda sudah membuka \\
& aplikasi Mobile SITTA dan ingin segera \\
& masuk dalam aplikasi ini. Lalu apa yang \\
& harus anda lakukan?
\end{tabular}

2 Anda sekarang sudah masuk ke aplikasi, lalu lakukan aktifitas login dengan input alamat email terdaftar dan password.

3 Jlka anda mengalami gagal masuk pada aktifitas login, lakukan pemilihan menu "Daftar" dan aplikasi akan memberi peringatan berupa pop-up/ alert dialog bahwa user diharapkan menghubungi admin SITTA untuk pendaftaran akun.

4 Jika anda mengalami gagal masuk pada aktifitas login, lakukan pemilihan menu "Lupa Password" dan aplikasi akan memberi peringatan berupa popup/ alert dialog bahwa user diharapkan menghubungi admin SITTA untuk melakukan perubahan kata sandi.

5 Anda sekarang sudah berhasil login dengan akun anda. Jalankan menu profil untuk mengakses menu yang

No Tugas/ Instruksi
tersedia pada aplikasi mobile SITTA
seperti Menu Informasi Bahan Ajar,
Menu Histori Bahan Ajar, Menu
Laporan Monitoring, dan Menu Rekap
Bajan Ajar.
Anda sekarang berada di Halaman
Utama Aplikasi. Pada halaman tersebut
terdapat search engine yang membantu
user untuk melakukan tracking
pengiriman bahan ajar dengan
menginput No. Billing pembayaran
bahan ajar sehingga informasi data
tracking bahan ajar mahasiswa beserta
detail status perjalanan paket bahan
ajar dapat terlihat.
Anda dapat memilih fasilitas "Detail"
pada data pribadi mahasiswa di menu
"Tracking". Fasilitas "Detail"
memberikan anda informasi Data
Pribadi Mahasiswa, Data Pengiriman
Bahan Ajar, dan Data Pembayaram.
Anda sekarang berada di menu
Informasi Bahan Ajar. Lakukan
pemilihan peragaan informasi stok
bahan ajar dengan plihan sub-menu
Pusat dan UPBJJ. Pada masing-
masing sub-menu Pusat da UPBJJ,
anda dapat mengakses tiga buah
informaasi yaitu Stok Item, Stok Paket,
dan Stok Bahan Ajar per lokasi.
Anda dapat mengakses laporan
monitoring dan memilih jenis laporan
yang akan ditampilkan (Laporan
Progress DO, Pengiriman DO, dan
Grafik Rekap Keluhan Bahan Ajar)
pada pada menu "Laporan Monitoring".
Ketika anda memilih menu "Histori
Bahan Ajar", lakukan input NIM
mahasiwa pada search engine maka
data histori transaksi bahan ajar
mahasiswa dapat terlihat.
a

2) Merancang Arsitektur Informasi Aplikasi Arsitektur informasi dibuat untuk menggambarkan keseluruhan alur aplikasi pada mobile SITTA. 


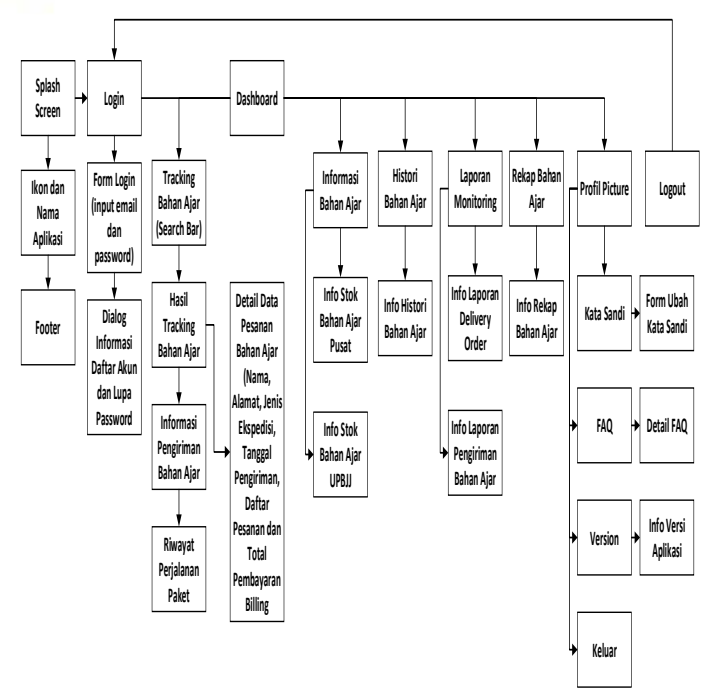

Gambar 2. Desain Arsitektur Informasi

\section{3) Merancang Desain Wireframe Aplikasi}

Tahapan ini dilakukan dengan membuat kerangka interaksi berdasarkan skenario serta kebutuhan-kebutuhan yang telah diuraikan sebelumnya [7] . Dalam kerangka tersebut berisi struktur tampilan dan layout aplikasi Mobile SITTA. Selain itu, pada tahap ini dilakukan pembuatan detail visual yaitu tipografi, padding, warna dan ikon yang menggambarkan tampilan awal desain. Hasil dari tahapan ini yaitu dalam bentuk low fidelty prototype (wireframe). Tools yang digunakan yaitu Whimsical untuk menggambarkan organisir konten, navigasi, layout, struktur dan susunan desain solusi dalam gambar hitam putih secara detail.

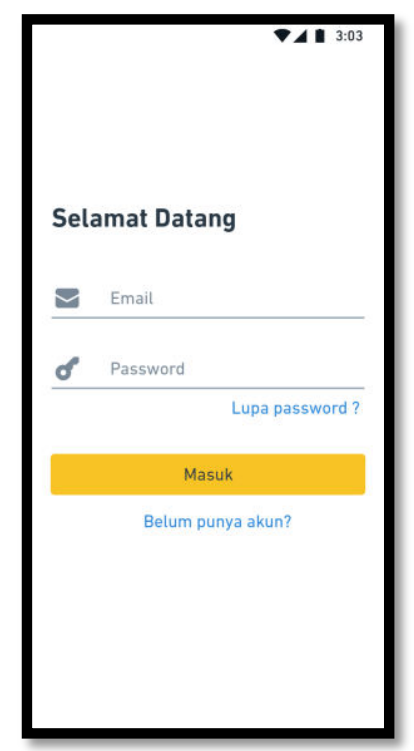

Gambar 3. Wireframe Halaman Login

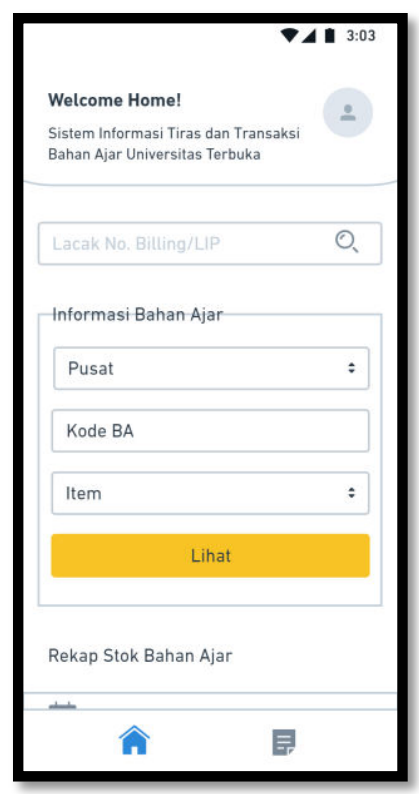

Gambar 4. Wireframe Halaman Menu Utama (Dashboard)

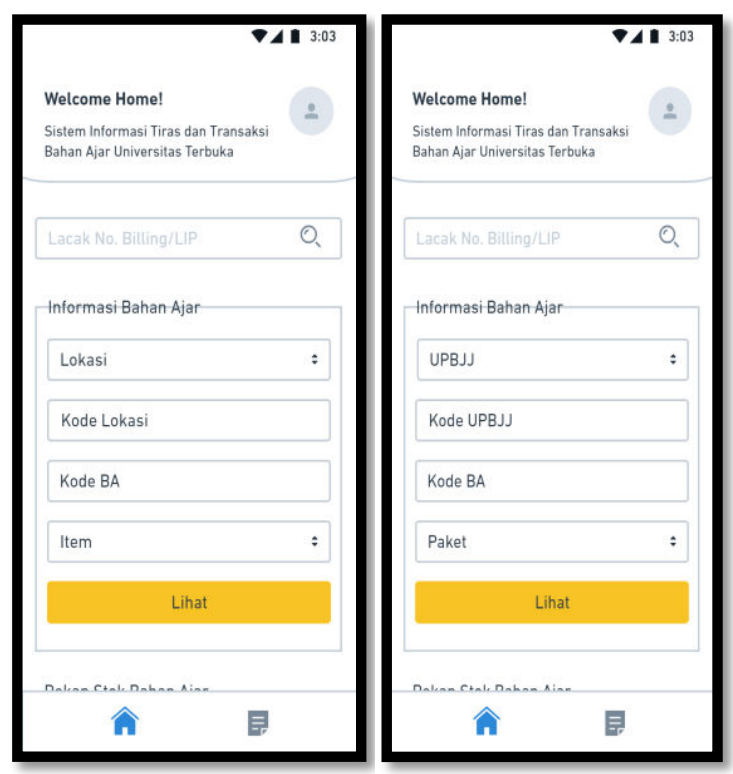

Gambar 5. Wireframe Halaman Informasi Bahan Ajar 


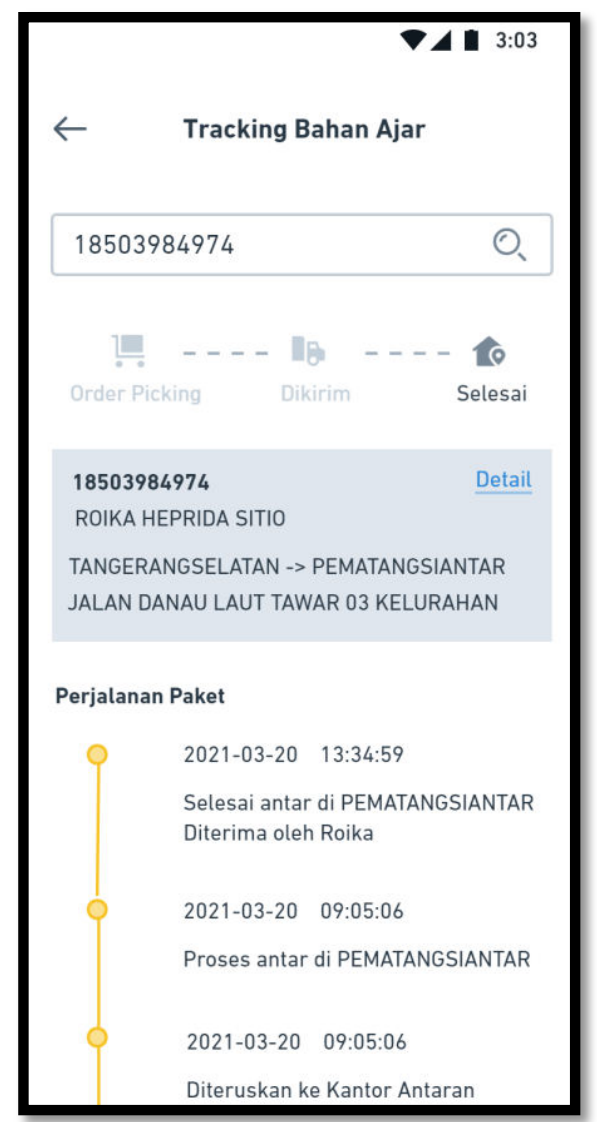

Gambar 6. Wireframe Halaman Tracking Bahan Ajar

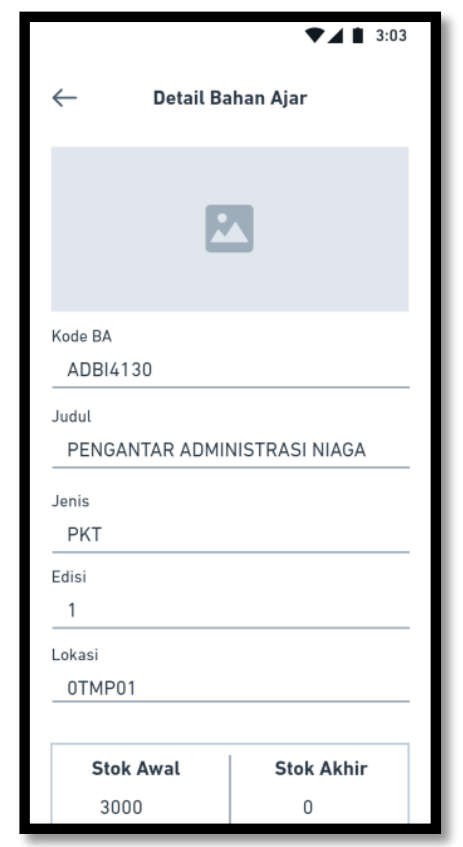

Gambar 7. Wireframe Halaman Detail Informasi Stok Bahan Ajar per Lokasi

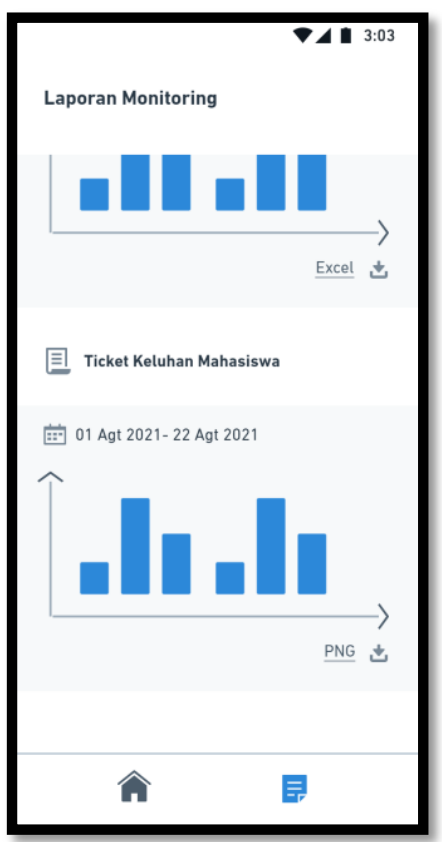

Gambar 8. Wireframe Halaman Laporan Progress DO Bahan Ajar

\section{4) Evaluasi Desain Solusi ke Pakar}

Evaluasi hasil desain dilakukan dengan mengunjui pakar UI/UX Designer sebagai expert/evaluator untuk menemukan permasalahan yang ada pada desain aplikasi mobile SITTA. Jumlah evaluator yang digunakan adalah satu orang pakar. Expert adalah seseorang yang dianggap mampu, menguasai, ahli dan dapat dipercaya dalam bidang keilmuannya. Terdapat satu professional/pakar UI/UX yang berpartisipasi pada evaluasi desain awal dan evaluasi desain solusi, yaitu seorang Tenaga Ahli Product Designer dari Unit Pengembangan Teknologi Informasi dan Komunikasi (UPT-TIK) Universitas Terbuka. Hasil dari evaluasi desain awal dituliskan dengan saran perbaikan yang direkomendasikan oleh pakar tersebut sehingga menghasilkan spesifikasi kebutuhan pengguna beserta solusi desain UI untuk selanjutnya didiskusikan dengan stakeholder Aplikasi Mobile SITTA.

Penelitian ini memiliki agenda review oleh pakar UI/UX Designer sebagai evaluator dengan catatan perbaikan yang diberikan oleh pakar tersebut. Review design ke pakar terdiri dari 2 tahap diantaranya yaitu Tahap 1 sebagai tahap review awal yang berisi catatan perbaikan oleh pakar dan Tahap 2 adalah review pakar berdasarkan hasil perbaikan sesuai catatan dari pakar dari Tahap 1. Berikut evaluasi desain oleh pakar pada Tahap 1 dan Tahap 2 seperti pada Tabel 2 dan Tabel 3. 
Tabel 2. Hasil Review Pakar Tahap 1

\begin{tabular}{|c|c|c|c|}
\hline Kegiatan & No & $\begin{array}{c}\text { Catatan } \\
\text { Perbaikan }\end{array}$ & Pakar \\
\hline $\begin{array}{l}\text { Review } \\
\text { Informasi } \\
\text { Arsitektur }\end{array}$ & 1. & $\begin{array}{l}\text { Tambahkan } \\
\text { proses untuk } \\
\text { menampilkan } \\
\text { dialog informasi } \\
\text { registrasi akun } \\
\text { Kurangi jumlah } \\
\text { layout }\end{array}$ & $\begin{array}{l}\text { Dicky } \\
\text { Fahlevi }\end{array}$ \\
\hline $\begin{array}{c}\text { Review } \\
\text { Wireframe }\end{array}$ & 3. & $\begin{array}{l}\text { Tambahkan histori } \\
\text { di pop up menu } \\
\text { profile picture }\end{array}$ & $\begin{array}{l}\text { Dicky } \\
\text { Fahlevi }\end{array}$ \\
\hline $\begin{array}{l}\text { Review } \\
\text { UI/UX di } \\
\text { Figma }\end{array}$ & 6. & $\begin{array}{l}\text { Drop shadow } \\
\text { button dibuat lebih } \\
\text { smooth. } \\
\text { Bedakan hirarki } \\
\text { tipografi pada } \\
\text { layout Detail } \\
\text { Informasi } \\
\text { Tentukan color } \\
\text { palette yang akan } \\
\text { digunakan }\end{array}$ & $\begin{array}{l}\text { Dicky } \\
\text { Fahlevi }\end{array}$ \\
\hline
\end{tabular}

Tabel 2 memiliki penjelasan sebagai berikut.

1. Pada tampilan login, perlu ditambahkan informasi bagaimana pengguna bisa memperoleh akun untuk dapat mengakses aplikasi. Sebagai UI Designer penting untuk memikirkan kondisi user ketika akan menggunakan aplikasi.

2. Schlatter (2013) memberi panduan untuk menyusun sebuah desain aplikasi dan membaginya kedalam beberapa komponen yang berpengaruh salah satunya ialah Hierarchy dan Type. Hirarki tipografi merupakan salah satu komponen yang berengaruh dalam menyusun sebuah desain aplikasi [8]. Hirarki tipografi mewakili sistem yang mengatur tipe atau jenis huruf yang menetapkan urutan kepentingan dalam data, memungkinkan pembaca untuk dengan mudah menemukan apa yang mereka cari dan menavigasi konten. Hirarki tipografi menciptakan kontras antara elemen. Desainer mencapai ini melalui penggunaan tipografi, ukuran, berat, huruf kapital dan huruf kecil, cetak tebal atau miring, orientasi dan warna.

3. Penelitian yang telah dilakukan oleh M. G. Hartadi (2020) menyatakan bahwa warna merupakan faKtor penentu keberhasilan desain UI ketika berinteraksi dengan pengguna [9]. Warna merupakan atribut desain yang sangat penting karena diterapkan ke dalam elemen desain untuk membangun kesan pengguna. Kesan terbentuk karena warna memberikan reaksi khusus pada otak manusia [10]. Sehingga dalam melakukan perancangan user interface, penentuan color palette sangat penting guna memudahkan proses implementasi wireframe ke dalam visual design.

Penulis melakukan perbaikan berdasarkan catatan yang diberikan oleh pakar ui/ux designer. Berikut hasil revisi pakar yang telah dilakukan setelah dilakukan perbaikan sesuai catatan pada Tahap 1.

Tabel 3. Hasil Review Pakar Tahap 2

\begin{tabular}{ccll}
\hline Kegiatan & No & $\begin{array}{l}\text { Hasil Catatan } \\
\text { Perbaikan }\end{array}$ & Keterangan \\
\hline & 1. & $\begin{array}{l}\text { Telah dilakukan } \\
\text { perubahan } \\
\text { penempatan fitur } \\
\text { Informasi }\end{array}$ & Sesuai \\
Arsitektur & 2. & $\begin{array}{l}\text { Telah dilakukan } \\
\text { perbaikan dengan } \\
\text { menambahkan } \\
\text { dialog informasi } \\
\text { registrasi akun }\end{array}$ & Sesuai \\
\hline Review & 3. & $\begin{array}{l}\text { Telah dilakukan } \\
\text { penambahan } \\
\text { history pop up }\end{array}$ & Sesuai \\
Wireframe & 4. & $\begin{array}{l}\text { Telah dilakukan } \\
\text { pengubahan pada } \\
\text { drop shadow button } \\
\text { Review }\end{array}$ & Sesuai \\
Ul/UX di & 5. & $\begin{array}{l}\text { Telah dilakukan } \\
\text { penentuan hirarki } \\
\text { tipografi dan color } \\
\text { palette }\end{array}$ & Sesuai \\
\hline Figma & & & \\
\hline
\end{tabular}

Tabel 3 memiliki penjelasan sebagai berikut.

1. Setiap ada yang diletakan di bottom navigation bar dan main menu di dashboard, berarti hal itu sangat penting.

2. Berdasarkan research user behaviour untuk simple app dengan target user pada kalangan orang dewasa, semua fitur lebih baik diletakan pada halaman utama. Sehingga tidak menimbulkan kebingungan user dalam menggunakan aplikasi.

3. User story penting dalam membangun design UI/UX. User story merupakan deskripsi mengenai kebutuhan sistem dalam bentuk bahasa natural yang dapat dengan mudah dipahami oleh end user yang tidak memiliki background TI. User story merupakan semi-structure language, karena sintaks harus diikuti dalam membuat user story. Dengan adanya user story, tim development dapat memahami fitur-fitur dari sistem yang akan dikembangkan dari sebuah user story. 
5) Perbaikan dan Pembuatan Desain Hasil Evaluasi ke Aplikasi Figma

Berdasarkan hasil pada tahapan evaluasi desain solusi ke pakar, diperoleh catatan dari pakar yang dijadikan acuan pada penelitian ini untuk memperbaiki rancangan desain user interface. Tahapan ini dilakukan untuk memperbaiki desain user interface aplikasi Mobile SITTA dalam bentuk high fidelty prototype yang sudah dilengkapi fungsionalitas dan kualitas desain yang lebih baik selayaknya sebuah produk jadi berdasarkan wireframe, tipografi, warna, padding dan ikon yang telah didefinisikan pada tahap sebelumnya. Hasil dari tahapan ini adalah high fidelty prototype. Tool yang digunakan adalah Figma. Pembuatan prototype yang dibuat dengan aplikasi Figma yang high-fidelity adalah prototype yang dibuat dengan desain interaktif yang memiliki tingkat kemiripan tinggi dalam hal detail dan fungsionalitasnya. Prototype adalah desain solusi yang telah siap dievaluasi untuk kemudian desain solusi dikomunikasikan kepada stakeholder aplikasi Mobile SITTA.

Perbaikan desain aplikasi Mobile SITTA dibuat berdasarkan pertimbangan dengan menggunakan ikon, tipografi, padding dan warna yang sudah ada pada desain aplikasi awal, akan tetapi terdapat beberapa perubahan dan penambahan untuk desain aplikasi yang baru sesuai kebutuhan. Berikut adalah beberapa contoh hasil perbaikan desain user interface aplikasi Mobile SITTA yang dapat dilihat pada Gambar 9 sampai dengan Gambar 14.

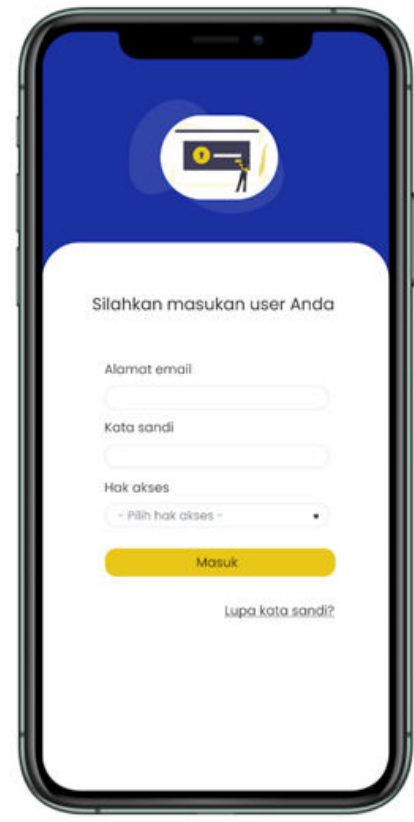

a) Desain Awal

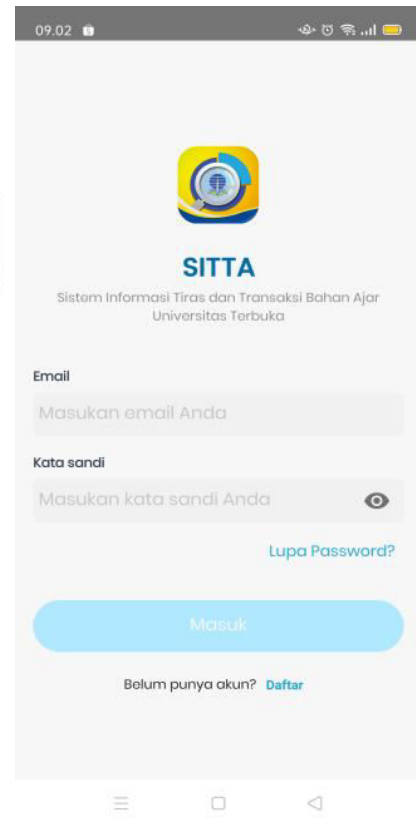

b) Desain Hasil Review

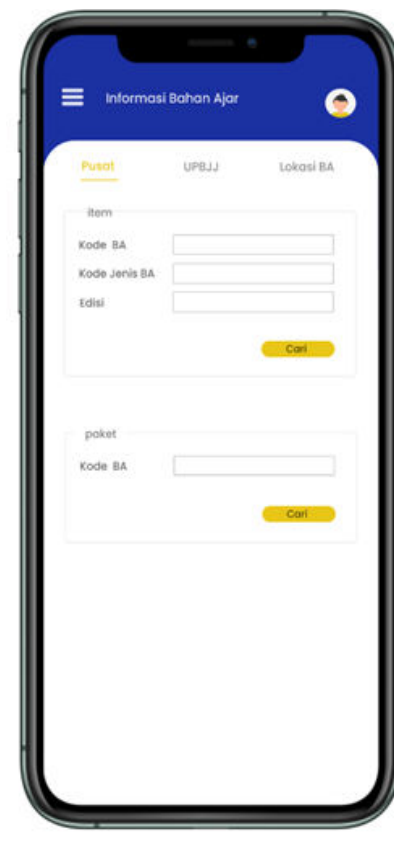

a) Desain Awal

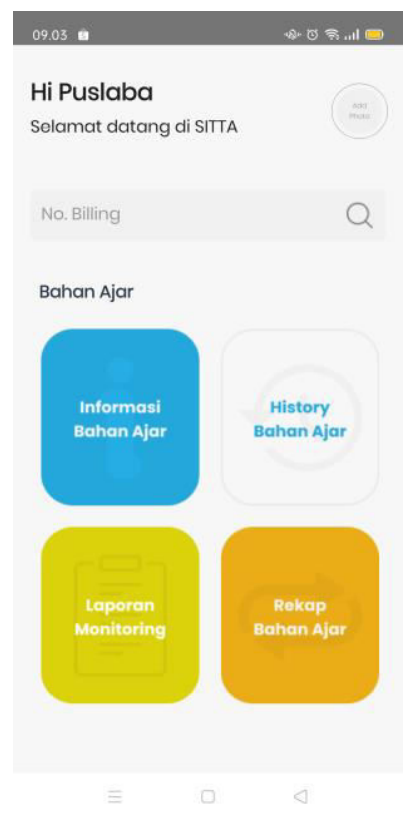

b) Desain Hasil Review

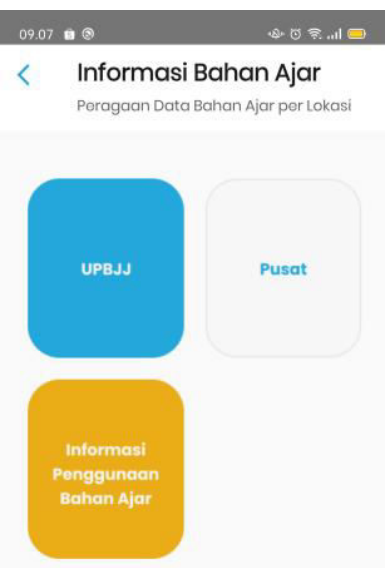

b) Desain Hasil Review
Gambar 11. Desain Halaman Informasi Bahan Aja 

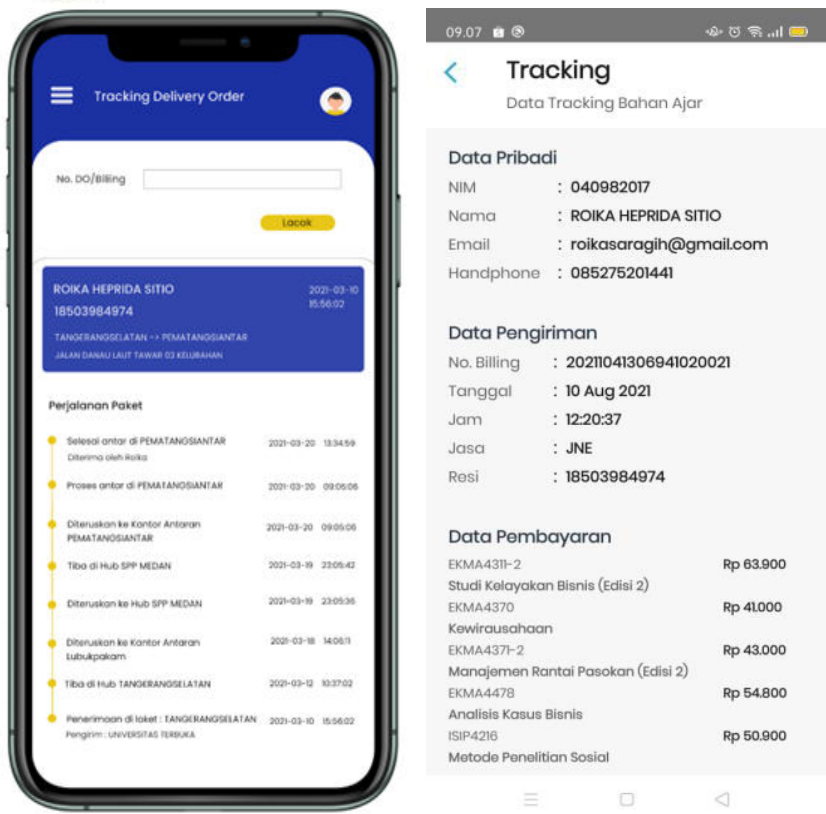

a) Desain Awal

b) Desain Hasil Review

Gambar 12. Desain Halaman Tracking Bahan Ajar
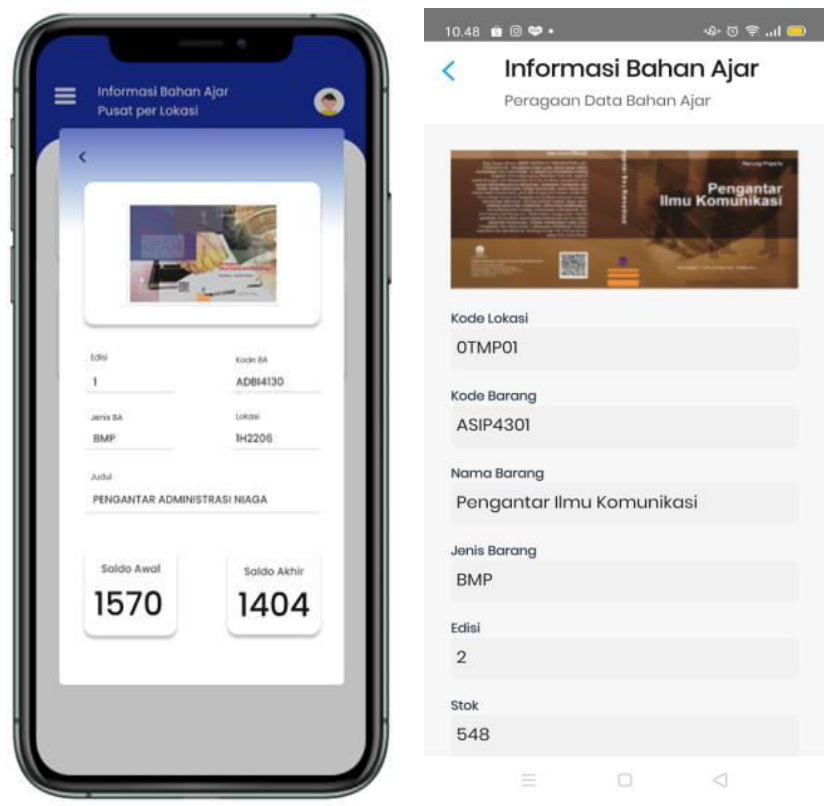

a) Desain Awal

b) Desain Hasil Review

Gambar 13. Desain Halaman Detail Informasi Stok Bahan Ajar per Lokasi
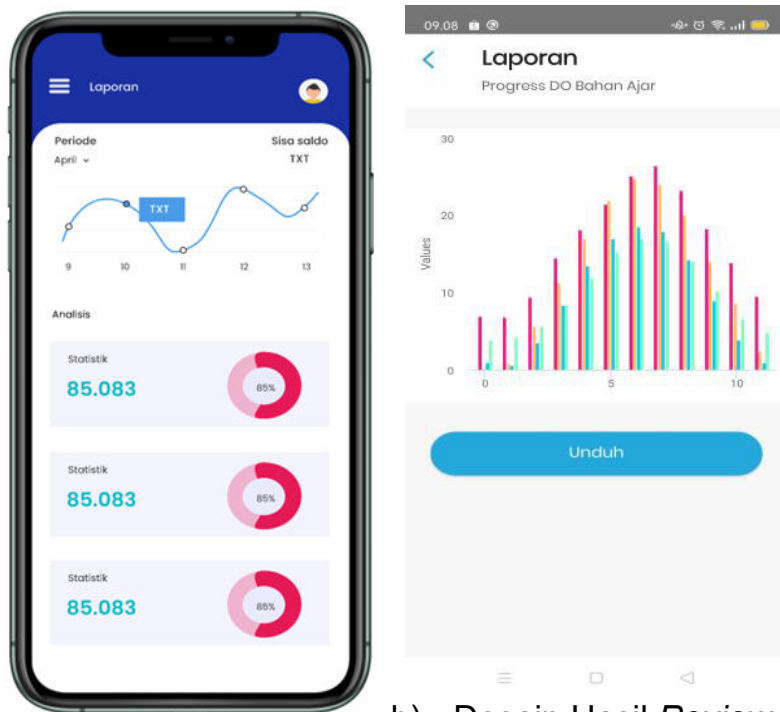

a) Desain Awal

b) Desain Hasil Review

Gambar 14. Desain Halaman Laporan Progress DO Bahan Ajar

\section{KESIMPULAN}

Perbaikan desain user interface dibuat berdasarkan pertimbangan dari desain awal aplikasi Mobile SITTA dan hasil evaluasi perbaikan desain dari pakar sebagai evaluator dengan berfokus pada user menggunakan pendekatan User Centered-Design yang meliputi observasi, studi literatur, user research, pembuatan arsitektur infromasi aplikasi, pembuatan desain low fidelity prototype (wireframe) dengan tools Whimsical, evaluasi desain ole pakar UI/UX hingga hasil akhir berupa pembuatan desain high fidelity prototype aplikasi dengan menggunakan tools Figma untuk diimplementasikan ke Android Studio sesuai dengan prinsip Google Material Design dengan berfokus pada user (Human Centered Design).

\section{REFERENSI}

[1] K. A. Seputra and G. Sandiasa, "Rancang Bangun Sistem Informasi Satgas Gotong Royong (Si Garong) Desa Adat Berbasis Mobile," J. Nas. Pendidik. Tek. Inform., vol. 9, no. 3, p. 338, 2020, doi: 10.23887/janapati.v9i3.25210.

[2] T. Prasetyaningtias, H. Muslimah AzZahra, and A. Hendra Brata, "Analisis Usability Pada Aplikasi Mobile EGovernment Layanan Aspirasi dan Pengaduan Online Rakyat (LAPOR!) 
Dengan Heuristic Evaluation," Anal. Usability Pada Apl. Mob. E-Government Layanan Aspir. dan Pengaduan Online Rakyat ( LAPOR!) Dengan Heuristic Eval., vol. 2, no. 11, pp. 4647-4653, 2018.

[3] R. Irwandana, A. D. Herlambang, M. C. Saputra, D. A. Fatah, A. P. Novitasari, and $\mathrm{H}$. Tolle, "Evaluasi dan Perancangan User Interface untuk Meningkatkan User Experience Menggunakan Metode Human-Centered Design dan Heuristic Evaluation Pada Aplikasi Ezypos," Rekayasa, vol. 2, no. 2, pp. 130-143, 2018.

[4] A. Dix, J. Finlay, G. D. Abowd, and R. Beale, INTERACTION. 2004.

[5] P. Morville, Information architecture for the World Wide Web, vol. 40, no. 06. 2003.

[6] A. I. Yunus, "Perancangan Desain User Interface Pada Aplikasi Siakad Dengan Menggunakan Metode User Centered Design.," User Interface, vol. 1, p. 95, 2018, [Online]. Available: http://repository.dinamika.ac.id/id/eprint/3 143/1/14410100068-2018-

STIKOMSURABAYA.pdf.
[7] D. N. Yastin, H. B. Suseno, and V. Arifin, "Evaluasi Dan Perbaikan Desain User Interface Untuk Meningkatkan User Experience Pada Aplikasi Mobile Siaran Tangsel Menggunakan Metode Goal Direct Design (Gdd)," J. Tek. Inform., vol. 13, no. 2, pp. 157-170, 2021, doi: 10.15408/jti.v13i2.18479.

[8] T. Schlatter and D. Levinson, "Visual Usability: Principles and Practices for Designing Digital Applications," Elsevier, 2013, [Online]. Available: https://www.elsevier.com/books/visualusability/schlatter/978-0-12-398536-1.

[9] M. G. Hartadi, I. W. Swandi, and I. W. Mudra, "Warna Dan Prinsip Desain User Interface (Ui) Dalam Aplikasi Seluler 'Bukaloka,"' J. Dimens. DKV Seni Rupa dan Desain, vol. 5, no. 1, p. 105, 2020, doi: 10.25105/jdd.v5i1.6865.

[10] U. Novena, "Tinjauan Warna Pada Visual Branding Warung Kopi Lokal," J. Dimens. DKV, vol. Vol. 4 No., pp. 205223, 2019. 